\title{
Utilization of Online Bibliographic Databases by Medical Doctors in a Teaching Hospital in Rwanda
}

\author{
Noël Korukire $^{1 *}$, Joseph Lune Ngenzi ${ }^{1}$, Malachie Tuyizere ${ }^{1}$, Etienne Nsereko ${ }^{1}$, David Basheija ${ }^{2}$, M. Claire Ineza ${ }^{3}$
}

1. School of Public Health, College of Medicine and Health Sciences, University of Rwanda

2. Centre of Language Enhancement, College of Medicine and Health Sciences, University of Rwanda

3. School of dentistry, College of medicine and Health Sciences, University of Rwanda

*corresponding author: Noel Korukire (koranoe1980@gmail.com)

\begin{abstract}
Background: Online bibliographic databases are important tools in health sector for both literature research and clinical practices. They provide current scientific insight for evidence based medicine and have the potential to support clinicians by providing them with the information they need in a timely fashion. Objective: This study was carried out to assess the utilization of online bibliographic databases by medical doctors at the University Teaching Hospital of Kigali. Methods: A mixed method (quantitative and qualitative) with a crosssectional design was used. Results: The study population was composed of 153 medical doctors and response rate was $53.5 \%$. The results of this study indicate that the most visited online bibliographic database is the Medline at the rate of $94 \%(\mathrm{~N}=82)$. More than $92 \%$ $(\mathrm{N}=82)$ of physicians at this hospital have computers with internet in their offices. Only $47.6 \%$ are able to use filters when they searching information to guide treatment. Physicians at the rate of $97.6 \%(\mathrm{~N}=80)$ have used online bibliographic databases in the past six months and $96 \%(\mathrm{~N}=80)$ were satisfied with their expectations. The constraints they face when searching information, is lack of full access to some scientific medical journals. A key informant said: "The challenge is that some medical journals provide only abstracts. In this case it is not easy for physicians to access full papers or full books to find information for patient care" Conclusion: The study concludes that physicians at University Teaching Hospital of Kigali use online bibliographic databases to guide treatment and Medline/Pubmed are the most used database. Nevertheless, there is gap in advanced searching skills among physicians. In terms of infrastructures the quality of internet bandwidth is another challenge. The study recommends continued sessions for literature search, as it is a key to practicing evidence-based medicine. It also recommends ensuring full access to scientific papers as well as good internet service delivery.
\end{abstract}

Keywords: Online bibliographic databases, medical doctors

\section{Introduction}

Online bibliographic databases refer to a catalog of bibliographic records with organized collection of references to published literature that includes journals, articles, conference proceedings, and books. [1] Literature shows some of the online bibliographic databases that contain medical and health related information include Cochrane, EMBASE, Up to Date and Medline among others, which can be used as source of information for patient care.[1] The online bibliographic databases are important tools in health sector for both literature research and clinical practices, as they provide current scientific insight for evidencebased medicine.[1,2]

Healthcare professionals have increasingly turned to online resources for updated information, and in the mid-1990s, electronic information began to be more widely available outside research environment.[3] The advantages of online information in clinical setting are known and they have been appreciated.[4] The online 
bibliographic databases have the potential to support clinicians by providing them with high quality and relevant information to guide treatment.[5,6] However, it is still underutilized due to different reasons.[9]

Traditionally, physicians used to search information when responding to patients' needs through their personal knowledge, printed journals, books and/ or consulting colleagues.[8] With the increase of Information Communication and Technology (ICT), a significant number of electronic resources have become available. [5,7] Their availability provided easy access to current and reliable information which could be used to respond to patient needs.[11]

The utilization of online bibliographic databases may lead to the application of evidence based medicine that would improve the quality of services for patients. $[10,11]$ Quite a lot of studies examined the use of internet to obtain clinical information for patient care. A study conducted in United State showed that 98\% of resident physicians used online resources for health related purpose.[12]

Studies indicate that health workers in developing countries have adopted the use of online databases to guide treatment as it has been adopted in developed countries.[10] A study conducted on access to online clinical resources by health workers in resourcelimited settings showed that the total usage of online bibliographic databases for patient care in Africa was $54 \%$. [13] However in developing countries, medical practitioners still face some challenges regarding the utilization of online resources to respond to patient needs. [4]

Lack of awareness, insufficient IT equipments, lack of continuous training, high cost of using the resources, lack of time[4] and a distinct preference for asking an expert colleague or consulting a print source have been reported as barriers to the use of online bibliographic databases.[3,14,7] Furthermore, lack of quick and easy access to information, and skills to identify and filtrate the useful information were also found as barrier to search reliable literatures for patient care.[15]

Rwanda has put in place policies and strategies to promote the use of Information Communication and Technology (ICT) for knowledge-based economy, through the National Information and Communication Infrastructure plan (NICI III) which aims at promoting internet connectivity countrywide as well as SMART
Rwanda document which promote the digitalization of all governmental services.[16] In addition, Rwanda is one of developing countries which has access to significant number of online journals via Health InterNetwork Access to Research Initiative (HINARI) [17] "A program developed in 2000 by World Health Organization with its partners and launched in 2002 to support health sector institutions in developing countries to access high quality and relevant scientific information for free or at reasonable cost'. [18]

Although Rwanda has free access to a huge number of online scientific journals and books through HINARI; policies and strategies to enhance ICT in different sectors including health are in place; several trainings on literature search for evidence based medicine to guide the treatment have been conducted, there is limited information regarding utilization of online bibliographic databases by Rwandan medical doctors, and also constraints experienced in utilizing these resources for clinical practices. Therefore, the aim of this study was to assess the utilization of online bibliographic databases by medical doctors in their daily practices related to patient care at the University Teaching Hospital of Kigali. Hence, this study was guided by the following research questions:

What are the online bibliographic databases that are mostly used by medical doctors when searching medical related information?

Do medical doctors at the University Teaching Hospital of Kigali have searching skills for medical related information in online bibliographic databases?

What are the challenges that medical doctors at the University Teaching Hospital of Kigali face when utilizing online bibliographic databases?

This study provided data on status of the utilization of online bibliographic databases in medical practice at the University Teaching Hospital of Kigali. The information from this study can be used by various decision makers during the planning and setting of various strategies aimed at promoting the utilization of online bibliographic databases in medical training institutions.

\section{Methods}

The study was conducted at the University Teaching Hospital of Kigali (UTHK) from January to September 2014. This hospital provides training, clinical research and technical support to district hospitals. A cross sectional study with census method, using both quantitative and qualitative approaches was used. In 
addition, purposive sampling method was used to select two key informants from the hospital's library. The study population was composed of 153 medical doctors (specialists, general practitioners, and residents). Out of 153 medical doctors, 82 returned the questionnaires, and the response rate was $53 \%$.

A self-administered questionnaire with closed-ended and a few open-ended questions was used for data collection. This study's research instrument was developed based on the questionnaires used in other related studies such as a study conducted in United State of America to assess the internet use and effects among health professionals and a study conducted in Finland to determine the use of electronic scientific information resources among medical and dental students. [19] Moreover, the authors of above mentioned studies provided rights to adapt these questionnaires. The member checkers in domains of medicine and Information Communication Technology and pre-test method were used for validation of the content of research instrument.

The Director General of the hospital and heads of different departments facilitated the researcher to reach the medical doctors in their respective departments. Questionnaires were distributed to respondents and the questions were answered accordingly, after which they were returned to the Heads of departments. The researcher then went back to pick the questionnaires in the offices of heads of departments. As some medical doctors did not return questionnaires, the strategies to have these questionnaires filled included a follow-up with them in respective departments, and to contact them on their cell phones numbers for appointments. However some of them were missed our appointments. In addition, the researcher met with key informants to collect additional qualitative data.

The researcher collected questionnaires from the departments to verify if there was no missing data, after which all data were entered into computer for analysis.
Quantitative data were analyzed using Statistical Package for Social Sciences (SPSS version 20) and Atlas Ti software were used to analyze qualitative data.

\section{Ethical considerations}

This study was approved by the Ethical Review Board of former Kigali Health Institute and the research committee of the University Teaching Hospital of Kigali. Respondents in their respective departments were clearly informed about the purpose of the study and were assured that their responses would remain confidential and will be used for academic purposes only. In addition, respondents consented to voluntarily participate in this study. Those who accepted to participate in this study signed the consent form without their names.

\section{Results}

Table 1. Social demographic characteristics of respondents

\begin{tabular}{lcc}
\hline Variable & Frequency & Percentage \\
\hline Sex & & \\
Male & 72 & 87.8 \\
Female & 10 & 12.2 \\
Total & 82 & 100 \\
\hline Age & & \\
{$[25-35[$} & 34 & 41.5 \\
[35-45[ & 32 & 39.0 \\
[45-55[ & 15 & 18.3 \\
$\geq 55$ & 1 & 1.2 \\
Total & 82 & 100 \\
\hline Category of physicians & & \\
Specialist & 33 & 40.2 \\
General practitioner & 20 & 24.4 \\
Residents & 29 & 35.4 \\
Total & 82 & 100 \\
\hline Working experience & & \\
$<1$ year & 1 & 1.2 \\
1-5 years & 67 & 81.7 \\
Above 5 years & 14 & 17.1 \\
Total & 82 & 100 \\
\hline
\end{tabular}

The table 1 indicates that $87.8 \%$ of respondents are male, $39 \%$ are aged between 35 to 44 years old, $40.2 \%$ of respondents are specialist physicians, and $81.7 \%$ have a working experience of 1 to 5 years 
The most widely used online bibliographic databases for searching medical related information

Table 2. The use and most widely visited online bibliographic databases by medical doctors for searching medical related information

\begin{tabular}{|c|c|c|c|c|c|c|c|}
\hline \multicolumn{3}{|c|}{ Computer procession(Laptop/desktop) } & \multirow{2}{*}{$\begin{array}{l}\text { Database } \\
\text { Cochrane }\end{array}$} & \multirow{2}{*}{$\frac{\text { Specialist }}{(\mathrm{N}, \%)}$} & \multirow{2}{*}{$\begin{array}{l}\text { Residents } \\
(\mathrm{N}, \%)\end{array}$} & \multirow{2}{*}{$\begin{array}{l}\text { General } \\
\text { practitioner } \\
(\mathrm{N}, \%)\end{array}$} & \multirow{2}{*}{$\frac{\text { Total }}{(\mathrm{N}, \%)}$} \\
\hline Variable & Frequency & Percentage & & & & & \\
\hline Yes & 76 & 92.7 & Yes & $21(51.2)$ & $14(34.1)$ & $6(14.6)$ & $41(51.3)$ \\
\hline No & 6 & 7.3 & No & $11(28.2)$ & $15(38.4)$ & $13(33.3)$ & $39(48.7)$ \\
\hline Total & 82 & 100 & Total & $32(79.4)$ & $29(72.5)$ & $19(47.9)$ & $80(100)$ \\
\hline \multicolumn{3}{|c|}{ Regular internet access } & Medline & & & & \\
\hline Yes & 82 & 100 & Yes & $31(40.7)$ & $27(35.5)$ & $18(23.6)$ & $76(95.0)$ \\
\hline No & 0 & 0 & No & $1(25.0)$ & $2(50.0)$ & $1(25.0)$ & $4(5.0)$ \\
\hline Total & 82 & 100 & Total & $32(65.7)$ & $29(85.5)$ & $19(48.6)$ & $80(100)$ \\
\hline \multicolumn{3}{|c|}{$\begin{array}{l}\text { Use of online bibliographic } \\
\text { databases in past six month }\end{array}$} & \multicolumn{5}{|l|}{ Up to date } \\
\hline Yes & $\begin{array}{l}\text { past six me } \\
80\end{array}$ & th 97.6 & Yes & $23(38.9)$ & $22(37.2)$ & $14(23.7)$ & $59(73.7)$ \\
\hline No & 2 & 2.4 & No & $9(42.8)$ & $7(33.3)$ & $5(23.8)$ & $21(26.3)$ \\
\hline Total & 82 & 100 & Total & $32(81.7)$ & $29(36.2)$ & $19(23.7)$ & $80(100)$ \\
\hline \multicolumn{3}{|c|}{ Meeting expectations } & Clinical evidence & & & & \\
\hline Yes & 77 & 96.3 & Yes & $9(39.1)$ & $9(39.1)$ & $5(21.7)$ & $23(28.7)$ \\
\hline No & 2 & 3.8 & No & $23(40.3)$ & $20(35.0)$ & $14(24.5)$ & $57(71.3)$ \\
\hline Total & 82 & 100 & Total & $32(79.4)$ & $29(74.1)$ & $19(45.2)$ & $80(100)$ \\
\hline
\end{tabular}

Table 2 indicates that $92.7 \%$ of respondents own computers (laptop/desktop) and $100 \%$ have access to internet. The same table shows that $97.6 \%$ of respondents have searched medical related information through online bibliographic databases in the past six month and $96.3 \%$ met their expectations when searching medical related information to guide the treatment. Medline $(95.0 \%)$ Up to Date $(73.7 \%)$ and Cochrane
(51.3\%) are the most widely used online bibliographic databases for searching medical related information at the University Teaching Hospital of Kigali. In addition, specialist physicians are the ones who visit the most these online bibliographic databases. For instance among 95\% users of searched medical related information through Medline, $40.7 \%$ are specialist medical doctors.

Searching skills when searching for medical information through online bibliographic databases

Table 3:Searching skills

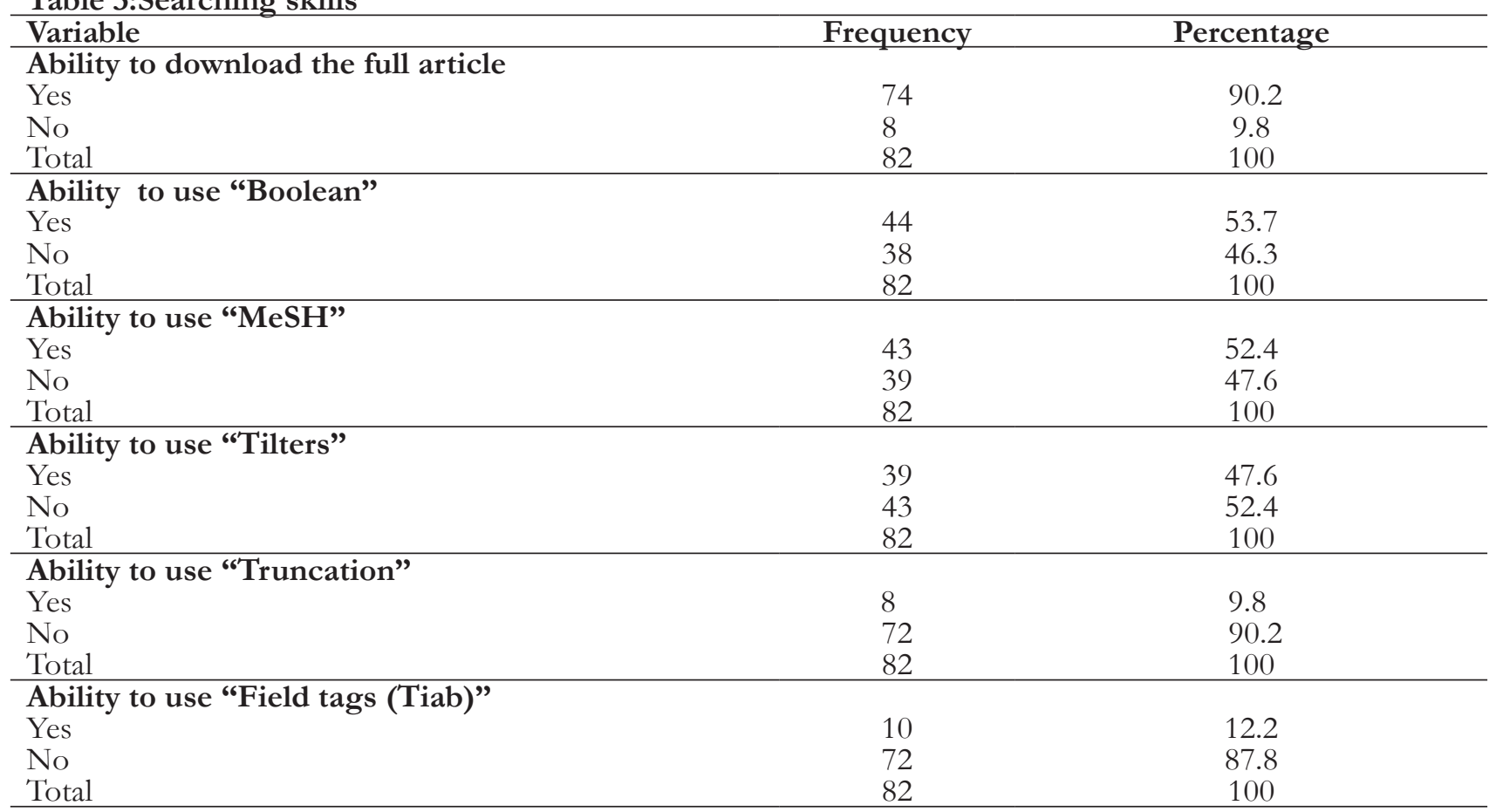


The table 3 shows that $90.2 \%$ have the ability of downloading article. However, only $53.7 \%$ of respondents are able to use searching options known as "Boolean" to connect search terms. This table indicates that only $52.4 \%$ of respondents are able to use Medical Subject Headings (MeSH) when searching articles. It also indicates that $52.4 \%$ don't use filtering when searching information in online bibliographic databases. More than $90.2 \%$ of respondents are not able to use truncation and only $12.2 \%$ are able to use filed tag “Tiab”.

\section{Challenges in utilization of online bibliographic databases at the University Teaching Hospital of Kigali}

Respondents indicated that the main challenge they faced while searching information to inform their choice of their patients' treatment was the availability of online resources because some of them were required to pay some money to access them. In addition, the speed (bandwidth) of internet was highlighted as another big challenge. One of the key informants argued: "some journals only provide abstracts. When it is the case, it is not easy for physicians to use online resources such as papers or full books to guide treatment". These have been supported by respondents. P1, P6 \& P10 said: "In some cases it is not easy to access full information as some journals only provide the abstracts" They also added that internet bandwidth is a challenge to them when they are searching literature to guide the decisions for responding to patient needs.

\section{Discussion}

This study shows that $98 \%$ of physicians at the University Teaching Hospital of Kigali have used online bibliographic databases and Medline (PubMed), Up to date, and Cochrane are the most visited online resources. Medline(Pubmed) represent 95\%, which is higher than the findings of another study conducted on "The level of Internet access and ICT training for health information professionals in sub-Saharan Africa which indicated that Medline (PubMed) was used by $45 \%$ of medical doctors. [20] There is a difference of the rate of utilization of online bibliographic databases between Rwanda and other sub-Saharan countries. This difference could be attributed to the awareness on availability of these online resources, as well as policies and investments in terms of subscriptions to journals that Rwanda has adopted,[16] a factor that is supported by literature which indicates that investments accelerate the use of Information Communication Technology. [21]

For those who used these online resources, 95\% met their expectations. This figure is in line with other studies conducted in the same field in Nigeria which indicated that $90 \%$ of respondents claimed they had obtained information from the online resources for patient care. This rate could be attributed to the availability of online books and scientific journals through Medline/PubMed. One of the respondents said: "Through Medline/PubMed you can access sufficient books and journals with good articles which contain scientific information". Also there is preference of the use of online resources rather than printed ones. [22] In addition, this database is rapidly updated, free, and easy to use.[23,24)] Furthermore, other editors also rely on Medline/PubMed as a source of information which has articles written by authors who are qualified as potential peer reviewers, and this contains various abstracts from several evidence-based journals, and e-books covering numerous biomedical disciplines.[23]

Table 3 shows that only $47.6 \%$ of respondents were able to filter the articles when searching for information to guide the treatment, and this lead to some of them relying on outdated information. Scholars reveal that physicians should be able to evaluate the validity and usefulness of the evidence, and use them to a patient's specific situation, [25] and this can lead a physician to take longer to access the required information without using advanced searching skills.

Findings indicate that general practitioners search less information to guide the treatment. This low rate could be attributed to busy schedules of medical doctors so they do not have enough time to practice these searching skills, as literature indicates that inadequate time is a barrier to information searching as it is time consuming.[26]

Regarding the access to online bibliographic databases, the study indicated that $100 \%$ at the University Teaching Hospital of Kigali confirmed the access to internet at their work places. This figure is in line with another study conducted in sub-Saharan countries which showed that $85.1 \%$ of respondents claimed they had access to internet at their work places.[20] However, the bandwidth of internet was highlighted by the respondents of this study as a challenge and this 
should be attributed to insufficient ICT infrastructures, [7] yet lack of access to internet or poor connectivity undermine physicians' ready access to up-to date information for patient care. [9, 4]

\section{Limitations}

Limitations of this study include the fact that these findings cannot be generalized in all clinical settings in the country since the study was conducted in one teaching hospital, and that the number of participants was small.

\section{Conclusion}

Regarding utilization of online bibliographic databases at University Teaching Hospital of Kigali, physicians at this hospital use online bibliographic databases to guide the treatment and Medline is the most widely used electronic resource physicians. However, there is still a gap in advanced searching skills where only few of them have the ability to use the searching options, yet literature searching skills is a key in practicing evidencebased medicine. In addition, physicians at University Teaching Hospital of Kigali face some challenges in using online resources such as lack of full access to some medical journals which provide abstracts only as well as limited internet bandwidth.

A positive point to note from this study is that the respondents are interested in utilization of online resources and this would definitely contribute to the success of any intervention in the improvement of the physicians' proficiency in using online bibliographic databases. Training in online literature search should be a module or units in all curriculums of medical schools to ensure future physicians and other health professionals have appropriate knowledge and skills in literature search to apply evidence-based medicine. Furthermore, the resources and internet speed should be upgraded.

\section{Acknowledgements}

Our gratitude goes to Prof. Kato Njunwa for his valuable contribution to this study, particularly in reviewing the proposal, and to Mr. Valens MBARUSHIMANA for his contribution in data analysis. Our special thanks also go to Ms. Liliane BIRASA for her contribution in data entry process.

\section{Conflict of interest}

All authors report no conflict of interest.

\section{Authors' contribution}

N.K was responsible for study conception and design, and data analysis .Ngenzi Joseph and Malachie contributed in searching literature to support the analysis, Etienne NSEREKO M.Claire INEZA contributed more in data interpretation and analysis while David BASHEIJA contributed in drafting of manuscript as well as English corrections.

\section{References}

1. Deodurg PM, Rana S, Brahma B. Overview of Journal Bibliographic Databases. 2013;2(12):92-7.

2. Thanuskodi S. Use of Internet and Electronic Resources for Medical Science Information: A Case Study. 2010;1(1):37-44.

3. Younger P. Review Article Internet-based information-seeking behaviour amongst doctors and nurses: a short review of the literature. 2010;2-10.

4. Masic I, Miokovic M, Muhamedagic B. Evidence Based Medicine - New Approaches and Challenges. 2008;16(4):219-25.

5. Ajuwon GA. Internet Accessibility and Use of Online Health Information Resources by Doctors in Training Healthcare Institutions in Nigeria. 2015;

6. Phua J, Kc S, Hj K, Manc M. Utility of the electronic information resource UpToDate for clinical decision-making at bedside rounds. 2012;53(November 2007):116-20.

7. Kwadzo G. Awareness And Usage Of Electronic Databases By Geography And Resource Development Information Studies Graduate Students In The University Of Ghana. 2015;(March).

8. Phua J. Use of traditional versus electronic medical- information resources by residents and interns Use of traditional versus electronic medical-information resources by residents and interns. 2014; (June 2007).

9. Ajuwon GA. Use of the Internet for health information by physicians for patient care in a teaching hospital in Ibadan, Nigeria. 2006;9:1-9.

10. Rizzo JD. Evidence-based medicine: can it be applied to stimulation of erythropoiesis for patients with malignancy ? 2005;18(3):439-48.

11. Grood C De. Adoption of e-health technology by physicians : a scoping review. 2016;335-44.

12. Valtis YK, Rosenberg J, Bhandari S, Wachter $\mathrm{K}$, Teichman M, Beauvais S, et al. Evidence- 
based medicine for all: what we can learn from a programme providing free access to an online clinical resource to health workers in resourcelimited settings. 2016;1-9.

13. Koller M, Grütter R, Peltenburg M, Fischer JE, Steurer J. Use of the Internet by medical doctors in Switzerland. 2009;251-5.

14. Bertulis R. Barriers to accessing evidence based information. Nursing standards. 2008;22(36):35-9.

15. MINICT. National ICT Strategy and Plan NICI 2015. 2015.

16. Aronson B. Brief communication. 2002;164-5.

17. WHO. HINARI. 2017.

18. Romanov K, Aarnio M. A survey of the use of electronic scientific information resources among medical and dental students. 2006;8:1-8.

19. Ajuwon GA, Rhine L. The level of Internet access and ICT training for health information professionals in sub-Saharan Africa. Heal Inf Libr J. 2008 Sep;25(3):175-85.

20. Annet K, William G, Bamuhiiga B. Factors affecting utilisation of electronic health information resources in universities in Uganda. 2012;59(June):90-6.
21. Groote BSL De, Box O, Drive OI. Measuring use patterns of online journals and databases. 2003;231-40.

22. Yuri A, Lilit G, Blackmore H, Kitas GD. Writing a narrative biomedical review : Considerations for authors, peer reviewers, and editors Writing a narrative biomedical review: considerations for authors, peer reviewers, and editors. 2016;(July 2011).

23. Cullen R, Clark M, Esson R. Evidence-based information-seeking skills of junior doctors entering the workforce: an evaluation of the impact of information literacy training during preclinical years. 2011;119-29.

24. Gruppen LD, Rana GK, Arndt TS. A Controlled Comparison Study of the Efficacy of Training Medical Students in Skills. 2005;80(10):940-4.

25. Nwafor-orizu OE, Onwudinjo OTU. Barriers to Optimal Utilization of Health Information Resources by Doctors in Nigeria. 2015;5(18):1-8. 